\title{
Estimating Fault Location Based on Fault Current in 20 kV Distribution System
}

\author{
Ricky Maulana \\ Department of Electrical Engineering \\ Universitas Negeri Padang \\ Padang, Indonesia \\ ricky.maulana@ft.unp.ac.id
}

\author{
Syarif Hidayat \\ Department of Electrical Engineering \\ Institut Teknologi Bandung \\ Bandung, Indonesia \\ syarif@ee.itb.ac.id
}

\begin{abstract}
The growth of the electric power system is currently rapid, causing an increase in the number and length of line to provide consumer services. In the line, there are often fault. Detection of fault location will speed up the repair process and can avoid more severe damage. Most studies refer to the fault location on the transmission line. But lately the determination of fault location in distribution system has begun to become a concern of researchers for the improvement of the quality of electricity services to consumers. This paper discusses about the determination of fault locations based on fault currents and the types of fault using data from the assumed $20 \mathrm{kV}$ distribution system model. The estimate location is obtained from the fault current simulation results using the polynomial approach each type of fault. The result fault location by ignoring the fault resistance has the largest error obtained $0.74 \%$. The fault location by including fault resistance needs an algorithm to looks for the right assumption fault resistance close to the unknown fault resistance that occurs.
\end{abstract}

Keywords-fault location, fault current, fault resistance, distribution system

\section{INTRODUCTION}

Electromagnetic The growth of the electric power system is currently taking place rapidly, causing an increase in the number and length of channels that are very much to meet consumer service. The fault locator helps identify the possible location of fault. Fault in the transient states are usually very difficult to see, so that with a fault locator can provide information on the possible location of fault that will speed up the repair process and can avoid more severe damage[1, 2]

Discussion of the fault location has long been an interesting discussion as research. Most studies refer to the fault location on the transmission line. This topic becomes important because fault in transmission line cause more severe damage than sub-transmission and distribution system. But lately the determination of the fault location in the distribution system has begun to become a concern of researchers for the improvement of the quality of electricity services to consumers [3].

Determination of the fault location distribution system usually uses a ground fault detector (GFD) that is installed at each substation. But the installation must be in each substation to find out the location of fault. In this article, the location of fault can be detected by simply installing this fault locator at the starting base of distribution system, so the cost can be saved as result of the installation of GFD at each substation.

This article contains the development of a method for detecting fault types, and estimating fault locations based on fault currents and distribution system databases, and considering fault resistance.

\section{BACKGROUND THEORY SHORT CRCUIT}

In determining the fault location, short circuit current value is required from the distribution system circuit model. Short circuit that occurs can be in a symmetrical and asymmetrical state. Symmetrical short circuit is the short circuit of the three line and asymmetrical short circuit can be in the form of one line to ground short circuit, double line short circuit and double line to ground short circuit. Shortcircuit current is also affected by fault resistance in the form of arching [4].

Fault is an abnormality in the electric power system which resulting an unbalanced current flow in the three-line system. Fault can be also defined as all circumstances that disrupt normal flow of current to the load [5].

Safety measures that can be taken to protect the electric power system by isolation of the affected part. In a modern electric power system, the process of eliminating short circuit is carried out automatically without any human intervention. The equipment that carries out this work is collectively known as a Protection System.

\section{A. Abbreviations and Acronyms}

The The magnitude of the fault current is expressed by the following equation [6]:

$$
I_{f}=\frac{V_{f}}{Z_{f}}
$$

$\mathrm{V}_{\mathrm{f}}$ : Pre-fault voltage of $1,0000 \mathrm{pu}$

$\mathrm{Z}_{\mathrm{f}}$ : Impedance fault

The post-fault voltage at bus - $\mathrm{n}$ is expressed by equation below:

$$
V_{n}=V_{f}-\frac{Z_{n k}}{Z_{k k}} V_{f}
$$

$Z_{n k}:$ Impedance between bus-n and bus-k $Z_{k k}:$ Impedance at fault bus-k

\section{B. Asymmetrical Fault}

Almost all of the fault that occurs in the electric power system is asymmetrical through impedance or open conductor. Asymmetrical fault such as single line to the ground, double line fault and double line to the ground fault. The fault current paths from line to line or from line to ground may or may not contain impedance. Every asymmetric fault causes an unbalanced current flow in the electric power system, the symmetric component method is very useful analysis to determine the current and voltage 
in all parts of the electric power system after fault happened [6].

According to the Fortescue theorem, three unbalanced phasors of a three-line system can be described into three balanced phasor systems namely positive sequence components in the equation using subscript 1 , negative sequence components in the equation using subscript 2 and zero sequence components in the equation using subscript $0[5]$.

Figure 1. shows the common fault schemes of various asymmetrical faults in electric power systems and the fault current is Ia, Ib and Ic.

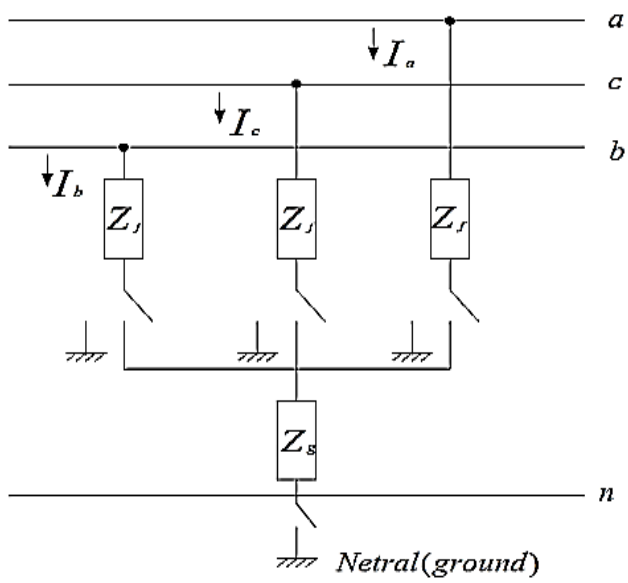

Fig. 1. Common fault diagram

The matrix equation for the symmetric of the voltage at fault with equation (3) follows:

$$
\left[\begin{array}{l}
V_{a 0} \\
V_{a 1} \\
V_{a 2}
\end{array}\right]=\left[\begin{array}{c}
0 \\
V_{f} \\
0
\end{array}\right]-\left[\begin{array}{ccc}
Z_{0} & 0 & 0 \\
0 & Z_{1} & 0 \\
0 & 0 & Z_{2}
\end{array}\right]\left[\begin{array}{c}
I_{a 0} \\
I_{a 1} \\
I_{a 2}
\end{array}\right]
$$

\section{Single Line to Ground}

For single line to ground fault, the following equation applied for determined fault current $\left(\mathrm{I}_{\mathrm{f}}\right)$ [7]:

$$
I_{f b}=0 ; I_{f c}=0 ; V_{k a}=Z_{f} I_{f a}
$$

the circuit in Figure 2 below:

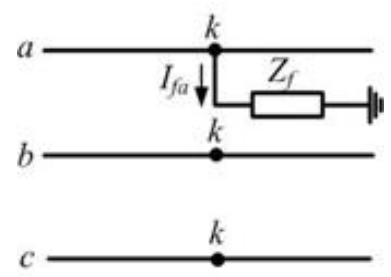

Fig. 2. Diagram for single line to ground

with $I_{f b}=0$ dan $I_{f c}=0$, symmetrical components of currents given by equation (5) below

$$
\left[\begin{array}{c}
I_{f a 0} \\
I_{f a 1} \\
I_{f a 2}
\end{array}\right]=\frac{1}{3}\left[\begin{array}{ccc}
1 & 1 & 1 \\
1 & a & a^{2} \\
1 & a^{2} & a
\end{array}\right]\left[\begin{array}{c}
I_{f a} \\
0 \\
0
\end{array}\right]
$$

Solving (5) we get $I_{f a 0}=I_{f a 1}=I_{f a 2}=\frac{I_{f a}}{3}$, thus change $I_{\mathrm{fa} 1}, I_{\mathrm{fa} 1}$ with $\mathrm{I}_{\mathrm{fa} 0}$ on equation (5), the following equation (6) is obtained:

$$
\left[\begin{array}{l}
V_{k a 0} \\
V_{k a 1} \\
V_{k a 2}
\end{array}\right]=\left[\begin{array}{c}
0 \\
V_{f} \\
0
\end{array}\right]-\left[\begin{array}{ccc}
Z_{k k 0} & 0 & 0 \\
0 & Z_{k k 1} & 0 \\
0 & 0 & Z_{k k 2}
\end{array}\right]\left[\begin{array}{c}
I_{f a 0} \\
I_{f a 1} \\
I_{f a 2}
\end{array}\right]
$$

By doing the multiplication and subtraction of the matrix mentioned, a similarity of the second column matrix is produced. By multiplying t of the two column matrices by row matrix [lll 111$]$ the following equation (7) is obtained:

$$
\begin{gathered}
V_{k a}=V_{k a 0}+V_{k a 1}+V_{k a 2} \\
V_{k a}=V_{f}-\left(Z_{k k 0}+Z_{k k 1}+Z_{k k 2}\right) I_{f a 0}
\end{gathered}
$$

Where,

$V_{k a}=Z_{f} I_{f a}=Z_{f}\left(I_{f a 0}+I_{f a 1}+I_{f a 2}\right)=3 Z_{f} I_{f a 0}$

thus fault current is obtained,

$$
I_{f a 0}=\frac{V_{f}}{Z_{k k 0}+Z_{k k 1}+Z_{k k 2}+3 Z_{f}}
$$

$I_{f a 0}:$ Fault current in zero sequence

$V_{f}:$ Pre-fault Volatge

The Thevenin equivalent of the sequence network is shown in figure 3.

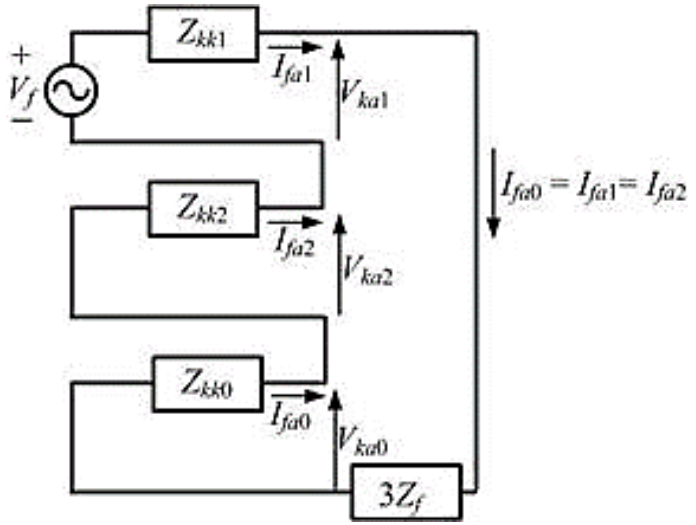

Fig. 3. Thevenin equivalent of a LG fault

\section{Line to Line Fault}

For line to line fault, the following equation applies [8]:

$$
I_{f a}=0 ; I_{f b}=-I_{f c}
$$




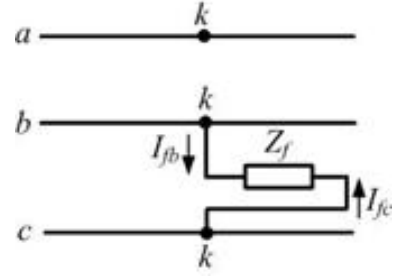

Fig. 4. Representation of L-L fault

because $\mathrm{I}_{\mathrm{fb}}=-\mathrm{I}_{\mathrm{fc}}$ and $\mathrm{I}_{\mathrm{fa}}=0$ so the symmetrical component can be represent by equation (11) below:

$$
\left[\begin{array}{l}
I_{f a 0} \\
I_{f a 1} \\
I_{f a 2}
\end{array}\right]=\frac{1}{3}\left[\begin{array}{ccc}
1 & 1 & 1 \\
1 & a & a^{2} \\
1 & a^{2} & a
\end{array}\right]\left[\begin{array}{c}
0 \\
I_{f b} \\
-I_{f b}
\end{array}\right]
$$

Thus,

$$
I_{f a 0}=0 ; I_{f a 2}=-I_{f a 1}
$$

For voltage,

$$
V_{k b}-V_{k c}=Z_{f} I_{b}
$$

Where,

$$
\begin{aligned}
V_{k b}-V_{k c} & =V_{k b 0}+V_{k b 1}+V_{k b 0}-V_{k c 0}-V_{k c 1}-V_{k c 2} \\
& =\left(V_{k b 1}-V_{k c 1}\right)+\left(V_{k b 2}-V_{k c 2}\right) \\
& =\left(a^{2}-a\right) V_{k a 1}+\left(a-a^{2}\right) V_{k a 2} \\
& =\left(a^{2}-a\right)\left(V_{k a 1}-V_{k a 2}\right)
\end{aligned}
$$

because $\mathrm{I}_{f a 0}=\mathrm{I}_{\mathrm{fb} 0}=0$ and $\mathrm{I}_{f a l}=-\mathrm{I}_{\mathrm{fb} 2}$ then equation can be obtained:

$$
\begin{aligned}
I_{f b} & =I_{f b 1}+I_{f b 2}=a^{2} I_{f b 1}+a I_{f b 2} \\
& =\left(a^{2}+a\right) I_{f b 1}
\end{aligned}
$$

A combination of equations (13) and (14) will be obtained,

$$
V_{k a 1}-V_{k a 2}=Z_{f} I_{f a 1}
$$

then the equation $\mathrm{I}_{\mathrm{fa}}$ of the sequence network in Figure 5 is obtained the equation:

$$
I_{f a 1}=-I_{f a 2}=\frac{V_{f}}{Z_{k k 1}+Z_{k k 2}+Z_{f}}
$$

$I_{f a 1}:$ Fault current in positive sequence

$I_{f a 2}:$ Fault current in negative sequence

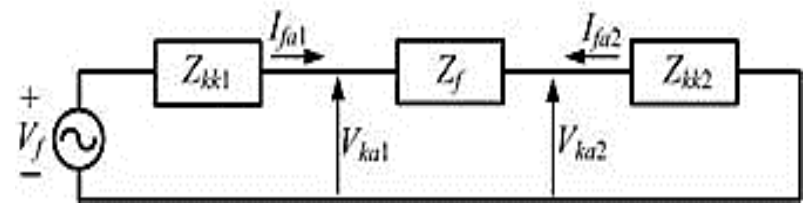

Fig. 5. Thevenin equivalent of LL fault

\section{E. Double Line to Ground}

For double line to ground fault, the following equation applies:

$$
\begin{aligned}
& I_{f a 0}=\frac{1}{3}\left(I_{f a}+I_{f b}+I_{f c}\right)=\frac{1}{3}\left(I_{f b}+I_{f c}\right) \\
& 3 I_{f a 0}=I_{f b}+I_{f c}
\end{aligned}
$$

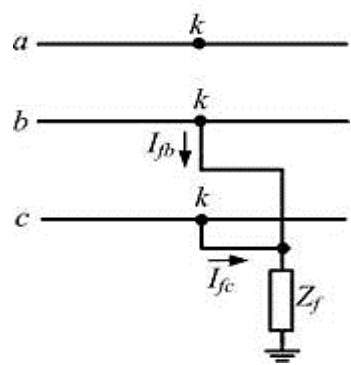

Fig. 6. Representation of LLG fault

Also voltages of lines $\mathrm{b}$ and $\mathrm{c}$ are given by,

$$
V_{k b}=V_{k c}=Z_{f}\left(I_{b}+I_{c}\right)=3 Z_{f} I_{f a 0}
$$

Therefore,

$$
V_{k a 012}=C\left[\begin{array}{c}
V_{k a} \\
V_{k b} \\
V_{k b}
\end{array}\right]=\frac{1}{3}\left[\begin{array}{c}
V_{k a}+2 V_{k b} \\
V_{k a}+\left(a+a^{2}\right) V_{k b} \\
V_{k a}+\left(a+a^{2}\right) V_{k b}
\end{array}\right]
$$

thus get the following two equations from,

$$
\begin{gathered}
V_{k a 1}=V_{k a 2} \\
3 V_{k a 0}=V_{k a}+2 V_{k b}=V_{k a 0}+V_{k a 1}+V_{k a 2}+2 V_{k b}
\end{gathered}
$$

Substituting (19) and (21) to (22), the following equation is obtained:

$$
V_{k a 1}=V_{k a 2}=V_{k a 0}-3 Z_{f} I_{f a 0}
$$

Because $\mathrm{I}_{f a}=0$ the following equation is obtained:

$$
I_{f a 0}+I_{f a 1}+I_{f a 2}=0
$$

Thevenin of the equivalent circuit in Figure 7 is obtained the following equation:

$$
I_{f a 1}=\frac{V_{f}}{Z_{k k 1}+\frac{Z_{k k 2\left(Z_{k k 0}+3 Z_{f}\right)}}{Z_{k k 2+Z_{k k 0}+3 Z_{f}}}}
$$

The zero and negative sequence currents can be obtained using the current divider principle as:

$$
\begin{gathered}
I_{f a 0}=-I_{f a 1} \frac{Z_{k k 2}}{Z_{k k 2+Z_{k k 0}+3 Z_{f}}} \\
I_{f a 2}=-I_{f a 1} \frac{Z_{k k 0}+3 Z_{f}}{Z_{k k 2+Z_{k k 0}+3 Z_{f}}}
\end{gathered}
$$

$I_{f a 1}:$ Fault current in positive sequence

$I_{f a 0}:$ Fault current in zero sequence

$I_{f a 2}:$ Fault current in negative sequence 


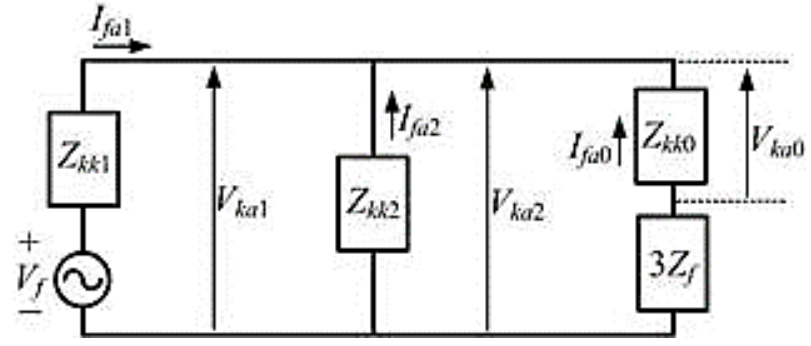

Fig. 7. Thevenin equivalent of $2 \mathrm{LG}$ fault

\section{F. Fault Impedance}

Short circuit current can be limited by fault impedance, however, there is a tradition fault impedance considering as a resistance, in order to compute the short circuit currents in a simple way [4]. Ground fault also involves a variety of impedances, commonly in the study of lineground fault consists of very small impedance and ignored. For high transmission and sub-transmission systems, fault impedance is ignored. But in a distribution system, very large impedances can occur. Contact with a tree can produce very large impedances. In most short-circuit studios, the fault impedance is assumed to be 0 (zero) to get the maximum fault current value. Also usually assumed with a pure resistor. The fault impedance is also the resistance of the arcs obtained from contributions from the following formulation (Warrington 1962) [9]:

Which,

$$
R=\frac{8750 l}{(0.305 I)^{1.4}}
$$

$\mathrm{R}$ : fault resistance $(\Omega)$

$\mathrm{L}:$ arc length $(\mathrm{m})$

I : r.m.s fault current (A)

\section{Design OF ESTIMATING FAULt LocAtion}

The stages of designing a estimate fault location are shown by the flow chart in Figure 8 below,

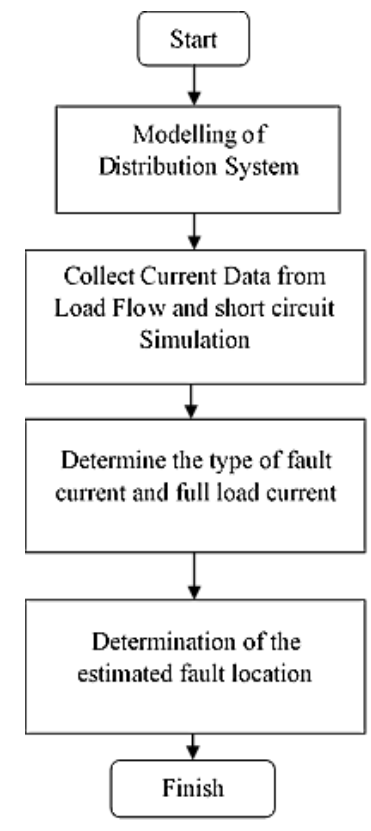

Fig. 8. Stages of estimating fault location

\section{A. Modeling distribution System.}

The distribution system model used is a $20 \mathrm{kV}$ distribution system consisting of 12 buses. Between the load buses are same distance of $2 \mathrm{~km}$ and the maximum load for each load bus is $250 \mathrm{kVA}$. And the main transformer used has 30 MVA power. The distribution system model is shown by the single line diagram in Figure 9 below:

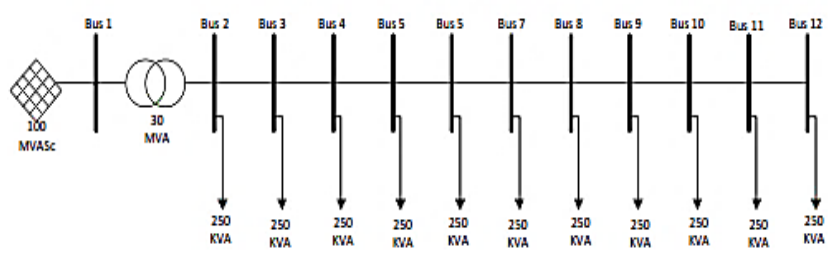

Fig. 9. Model of distribution system

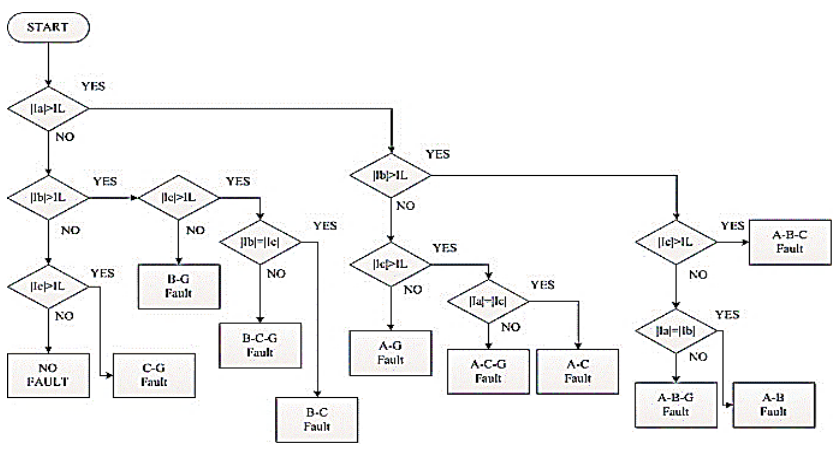

Fig. 10. Determine type of fault current

\section{B. Load Flow and Short Circuit Simulation}

Load flow and short circuit simulation is performed to find out the difference between the load flow current and the short circuit current. A load flow simulation is carried out with the same loading variation per bus starting from $10 \%$ loading to full load. Load flow simulation is performed to determine the maximum current limit. Thus, the current that exceeds $150 \%$ maximum current of load flow can be categorized as a short circuit current. Short circuit simulation performed with 4 types of fault:

- $\quad$ Short-circuit one line to ground (L-G)

- Short circuit double line (L-L)

- Short circuit double line to ground (L-L-G)

- 3 line short circuit symmetrical (L-L-L)

\section{Determine type of current}

Before determining the estimate fault location, the type of fault is determined first. After knowing the type of fault, the program will run according to the type of fault. For example, if fault type is a single line to ground fault, the program will run an algorithm for single line to ground fault and then calculate the estimation of fault location. For the process of determining the type of fault is shown by the flow chart in figure 10. 


\section{Estimating of Foult Location}

The short circuit simulation data is converted to the polynomial equation approaching with the relationship between fault current and fault location for each type of fault. So to determine the estimated location obtained from the polynomial equation approaching of the detected fault current and type of fault.

\section{SimULATION AND RESUlT}

This simulation aims to determine the boundary between the load flow current and short circuit current which will be used as a determination of fault type and determine the fault location from fault type that occurs.

\section{A. Load Flow simulation}

In load flow simulation, loading is carried out from 25 $\mathrm{kVA}$ to a maximum loading of $250 \mathrm{kVA}$ with the same load variations given for each bus. The results of load flow simulation are shown in figure 11.

\section{B. Short Circiut Simulation}

Short circuit simulation is conducted to determine the relationship between short circuit current and fault location in distribution system model used. Fault are given on each load bus with variations in fault type. Short circuit is performed with 4 types of fault: Short-circuit one line to ground (L-G); Short circuit double line (L-L); Short circuit double line to ground (L-L-G); 3 line short circuit symmetrical (L-L-L). The result of 4 type fault is given on figure 12 .

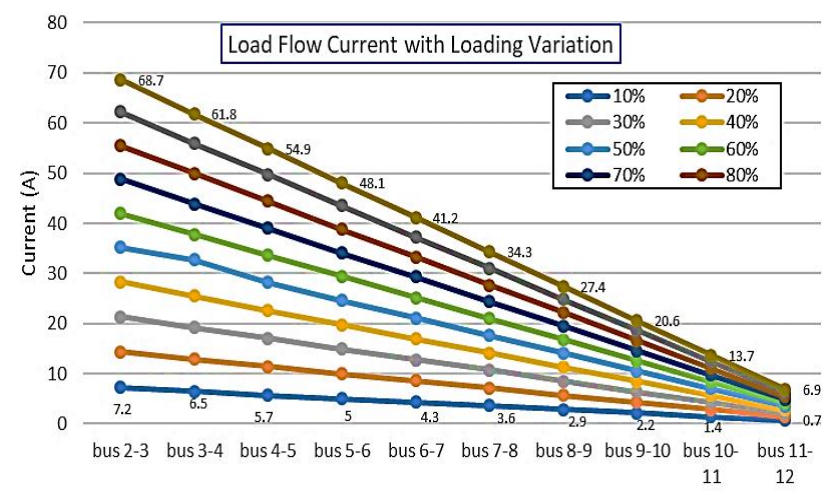

Fig. 11. Graph of load flow simulation with load variations

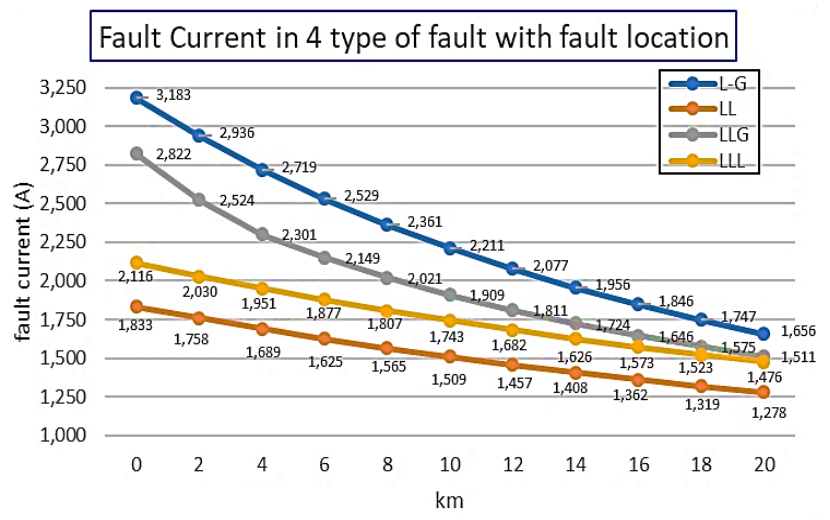

Fig. 12. Simulation results of short circuit with different type of fault

\section{Estimating of Fault Location}

Polynomial equation will calculate the estimated fault location based on fault current and fault type. The result of estimating fault location can be shown on the table below:

TABLE I. RESUlt OF ESTIMATING FAULt Location

\begin{tabular}{|c|c|c|c|c|c|}
\hline \multirow{2}{*}{$\begin{array}{l}\text { Type } \\
\text { of } \\
\text { Fault }\end{array}$} & \multirow{2}{*}{$\begin{array}{c}\text { Fault } \\
\text { Current } \\
(\text { kA) }\end{array}$} & \multicolumn{4}{|c|}{ Fault Location } \\
\hline & & $\begin{array}{c}\text { Actual } \\
(\mathbf{k m})\end{array}$ & $\begin{array}{c}\text { Estimating } \\
(\mathbf{k m})\end{array}$ & $\begin{array}{c}\text { Error } \\
(\%)\end{array}$ & $\begin{array}{c}\text { Error } \\
\text { (meter) }\end{array}$ \\
\hline \multirow[t]{5}{*}{ LG } & 2.719 & 4 & 3.991 & 0.235 & 9.407 \\
\hline & 2.361 & 8 & 7.989 & 0.137 & 10.938 \\
\hline & 2.077 & 12 & 11.988 & 0.098 & 11.786 \\
\hline & 1.846 & 16 & 15.997 & 0.022 & 3.441 \\
\hline & 1.656 & 20 & 19.992 & 0.040 & 7.934 \\
\hline \multirow[t]{5}{*}{$\mathbf{L L}$} & 1.689 & 4 & 4.002 & 0.045 & 1.813 \\
\hline & 1.565 & 8 & 8.001 & 0.012 & 0.982 \\
\hline & 1.457 & 12 & 11.995 & 0.043 & 5.208 \\
\hline & 1.362 & 16 & 16.006 & 0.034 & 5.511 \\
\hline & 1.278 & 20 & 20.001 & 0.005 & 1.030 \\
\hline \multirow[t]{5}{*}{ LLG } & 2.301 & 4 & 4.030 & 0.740 & 29.582 \\
\hline & 2.021 & 8 & 7.982 & 0.228 & 18.257 \\
\hline & 1.811 & 12 & 12.018 & 0.149 & 17.909 \\
\hline & 1.646 & 16 & 15.984 & 0.097 & 15.542 \\
\hline & 1.511 & 20 & 20.009 & 0.043 & 8.571 \\
\hline \multirow[t]{5}{*}{ LLL } & 1.951 & 4 & 3.997 & 0.072 & 2.877 \\
\hline & 1.807 & 8 & 8.013 & 0.161 & 12.903 \\
\hline & 1.682 & 12 & 12.008 & 0.070 & 8.456 \\
\hline & 1.573 & 16 & 15.998 & 0.013 & 2.100 \\
\hline & 1.476 & 20 & 19.998 & 0.012 & 2.347 \\
\hline
\end{tabular}

\section{The Effect Of Fault Resistance}

In short circuit usually have fault resistance, and the value of fault resistance cannot be predicted. In the simulation, fault resistance causes a large difference value of fault current compared to simulation results without adding fault resistance. The fault resistance used is derived from statistical data on 4 (four) substations belonging to North-Karelian Electricity and Häme Electricity recorded during 1994-1996 [3].

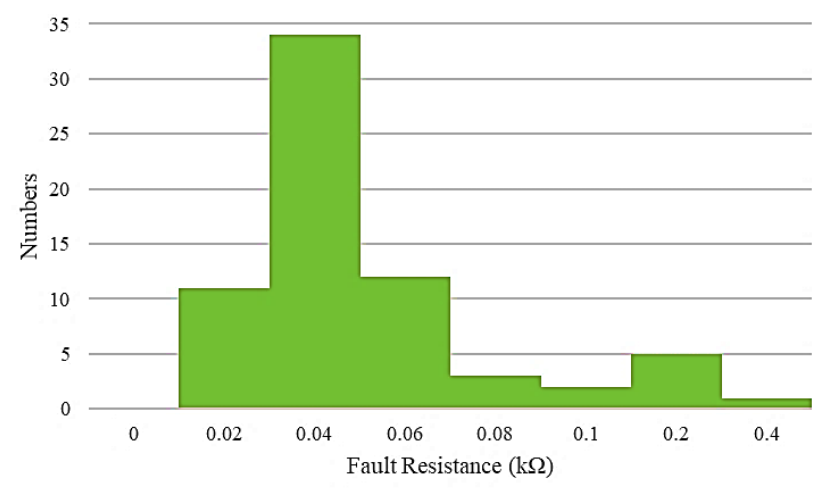

Fig. 13. Fault resistance recorded during 1994-1996 [9]

Based on the statistic above, it can be seen that the most frequent fault resistance is $0.04 \mathrm{k} \Omega$ or $40 \Omega$. And also based on the statistic above the assumed fault resistance used in this paper is between 20 and $100 \Omega$. Polynomial equations are also made for the assumption of fault resistance.

The fault resistance causes the fault current to become smaller than the fault current without fault resistance. As a result of fault resistance causes estimated location negative for fault resistance that occurs below the assumed 
resistance value. To improve the results of estimated fault locations, the algorithm is made for assumption fault resistance. This algorithm looks for the right assumption fault resistance close to the fault resistance that occurs. so the estimated error of the fault location is reduced due to unknown fault resistance as shown by the following flowchart:

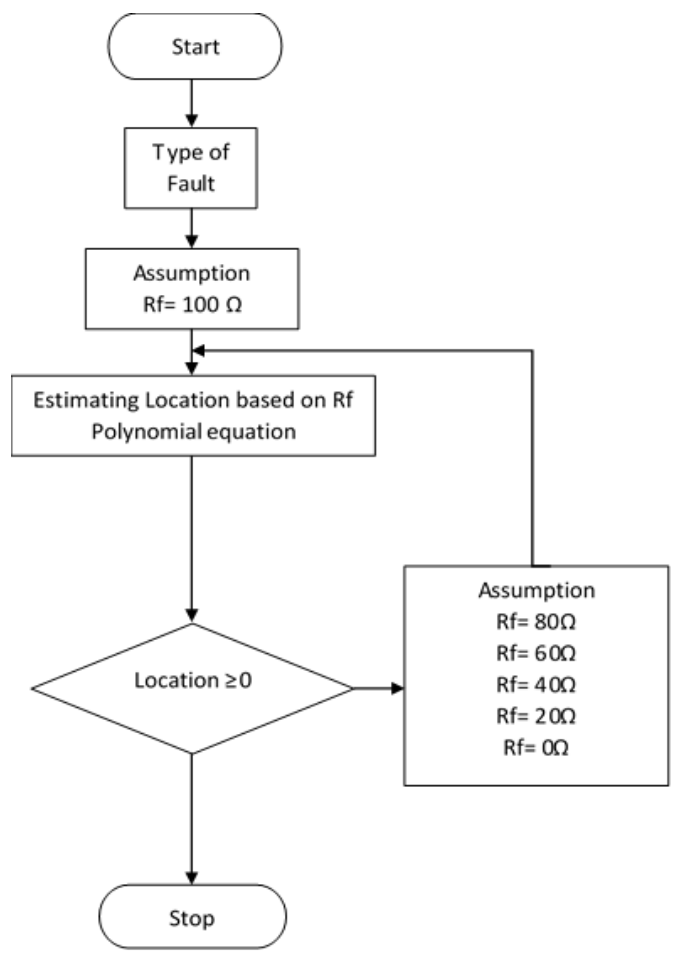

Fig. 14. Flow diagram for improving the estimated fault location assuming a lot of fault resistance

In simulation, fault resistance effects of fault current for line-to-ground and line-to-ground fault type. After using the algorithm for determining an estimate of fault location, the results of estimated locations for the line to ground fault in variations fault resistance are shown in figure 15 below:

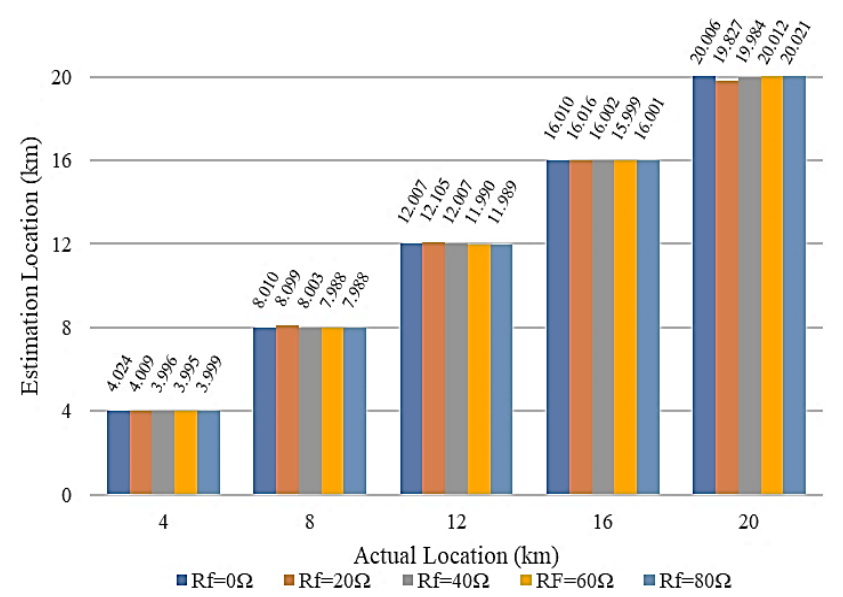

Fig. 15. Results of estimated location for line to ground fault in variations of fault resistance after algorithm repaired

Results of estimated locations for double line to ground fault are shown in the following figure 16:

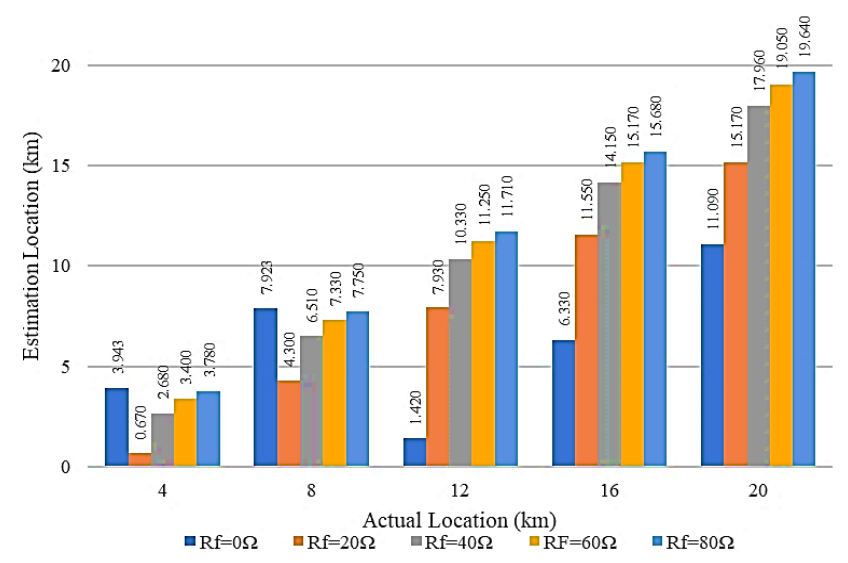

Fig. 16. Results of estimated location for double line to ground fault in variations of fault resistance after algorithm repaired

The results for line to ground fault are very accurate with the average error occurring is $0,211 \%$, but for results double line to ground not accurate yet with average errors is $22,105 \%$. Line to ground has big average error occurs because the little difference fault current for each assumption of fault resistance at the same location is too small. So, the algorithm calculates the polynomial equation closest to the assumed fault resistance that it should be.

\section{CONCLUSION}

According to the estimate fault location based on fault current, it can be concluded that the estimated fault location can be done. The estimated fault location by ignoring fault resistance, the biggest error is $0.74 \%$ and it can be concluded that the estimation is very accurate. To estimate fault location by considering fault resistance, the algorithm used is different. Results after algorithm change, the highest error for line to ground fault is $1.238 \%$ and double line to ground is $88.167 \%$. The error for double line to ground happened because the difference fault current for the assumption of fault resistance at the same location is very small. And algorithm calculates the polynomial equation closest assumed fault resistance that it should be.

\section{REFERENCES}

[1] S. M. Brahma, "Fault location in power distribution system with penetration of distributed generation," IEEE Trans. Power Deliv., vol. 26, no. 3, pp. 1545-1553, 2011.

[2] . S. and R. Maulana, "Program Aliran Daya Untuk Analisis Sistem Distribusi Dengan Penambahan Photovoltaic Model," J. Nas. Tek. Elektro, vol. 1, no. 1, pp. 1-10, Oct. 2012.

[3] M. S. Sachdev, R. Das, and T. S. Sidhu, "Determining locations of faults in distribution systems," in IEE Conference Publication, 1997, no. 434, pp. 188-191.

[4] V. De Andrade and E. Sorrentino, "Typical expected values of the fault resistance in power systems," in 2010 IEEE/PES Transmission and Distribution Conference and Exposition: Latin America, T and D-LA 2010, 2011, pp. 602-609.

[5] W. D. Stevensons and I. Kemal, Analisis Sistem Tenaga Listrik, 4th ed. Jakarta: Erlangga, 1994.

[6] H. Saadat, Power System Analysis. New York: McGraw-Hill, 1993.

[7] “Chapter 8: Unsymmetrical Faults." [Online]. Available: https://nptel.ac.in/content/storage2/courses/108104051/ui/Course_ home-8.htm.

[8] J. H. Teng, "Unsymmetrical short-circuit fault analysis for weakly meshed distribution systems," IEEE Trans. Power Syst., vol. 25, 
Journal on Advanced Research in Electrical Engineering, Vol. 4, No. 2, Oct. 2020

no. 1, pp. 96-105, 2010.

[9] S. Hänninen, "Single phase earth faults in high impedance grounded networks Characteristics, indication and location," VTT Publ., no. 453, pp. 2-78, 2001. 